\title{
Two- and Three-Dimensional Anatomy of Paranasal Sinuses in Arabian Foals
}

\author{
Sadullah BAHAR ${ }^{1)}$, Durmus BOLAT ${ }^{2) *}$, Mustafa Orhun DAYAN ${ }^{1)}$ and Yahya PAKSOY ${ }^{3)}$ \\ 1)Department of Anatomy, Faculty of Veterinary Medicine, Selcuk University, Konya, Turkey \\ ${ }^{2)}$ Department of Anatomy, Faculty of Veterinary Medicine, Kirikkale University, Kirikkale, Turkey \\ ${ }^{3)}$ Department of Radiology, Faculty of Medicine, Istanbul Medipol University, Istanbul, Turkey
}

(Received 24 January 2013/Accepted 21 August 2013/Published online in J-STAGE 4 September 2013)

ABSTRACT. The 2- and 3-dimensional (3D) anatomy and the morphometric properties of the paranasal sinuses of the foal have received little or no attention in the literature. The aim of this study was to obtain details of the paranasal sinuses using multiplane CT imaging to create 3D models and to determine morphological and morphometric data for the sinuses using the 3D models. The heads of five female foals were used in this study. The heads were scanned using computed tomography (CT) in the rostrocaudal direction. After the heads had been frozen, anatomical sections were obtained in the scan position. The 3D models of sinuses and the skull were prepared using MIMICS ${ }^{\circledR}$. These models were used to assess the surface area and volume of the sinuses, the width, height and orientation of the apertures connecting these sinuses and finally the planar relation of the sinuses with the skull. The right and left sides of all anatomical structures, except the sphenoid sinuses, had symmetric organization on CT images and anatomical sections. The total sinus surface area and volume on both sides were $214.4 \mathrm{~cm}^{2}$ and $72.9 \mathrm{~m} l$, respectively. The largest and the smallest sinuses were the frontal sinus $(41.5 \mathrm{~m} l)$ and the middle conchal sinus $(0.2 \mathrm{ml})$, respectively. It was found that the planes bounding the sinuses passed through easily palpable points on the head. In conclusion, 3D modeling in combination with conventional sectional imaging of the paranasal sinuses of the foal may help anatomists, radiologists, clinicians and veterinary students.

KEY WORDS: 3D modeling, Arabian horse, CT, morphometry, paranasal sinus.

doi: 10.1292/jvms.13-0172; J. Vet. Med. Sci. 76(1): 37-44, 2014

The paranasal sinuses of horses consist of 7 parts, the rostral maxillary sinus (RMS), caudal maxillary sinus (CMS), frontal sinus (FS), dorsal conchal sinus (DCS), middle conchal sinus (MCS), ventral conchal sinus (VCS) and sphenopalatine sinuses (SPS) [14, 24]. Given their complex architecture, location, relationships and neighborhoods, the paranasal sinuses are important structures in the head of the horse.

Computed tomography (CT) is a scanning method used to determine sectional details of many complex body parts, including the head $[1,7]$. Although CT has widespread use in veterinary medicine, especially in small animals, it has limited use in equine clinics, because of the lack of availability of appropriate devices and the current devices being able to scan only the head and distal legs of horses [17, 19, 37]. CT is used in horses to investigate the gross sectional anatomy $[1,7]$ of the head as well as pathologic conditions arising in this area, such as sinusitis [36, 37], alveolitis [13], trauma [3, $22]$ and carcinomas $[6,42]$. These studies have investigated horses of different breeds and ages other than Arabian foals, primarily via transverse CT images and have provided many details about the paranasal sinuses [7, 23, 29, 36, 37].

*Correspondence to: Bolat, D., Department of Anatomy, Faculty of Veterinary Medicine, Kirikkale University, Kirikkale, Turkey. e-mail: bolatdurmus@yahoo.com

(C)2014 The Japanese Society of Veterinary Science

This is an open-access article distributed under the terms of the Creative Commons Attribution Non-Commercial No Derivatives (by-ncnd) License $<$ http://creativecommons.org/licenses/by-nc-nd/3.0/>.
In recent years, 3-dimensional (3D) models, which have been prepared using CT images, have been used to determine anatomic details of the paranasal sinuses visually $[5,10,35$, 41] to obtain morphometric data, such as volume, length, width and height $[15,16,20,28,39]$ and to plan surgical procedures that will be performed in this region $[21,26]$. The purpose of the present study was to define the multiplane CT sections, anatomical sections and 3D anatomy of paranasal sinuses in Arabian foals. The objectives were, first, to establish the multiplane cross-sectional anatomy by comparing CT images with anatomical sections and, second, to establish 3D anatomical models to enable detailed descriptions of paranasal sinus morphology, morphometry and configuration to be developed.

\section{MATERIALS AND METHODS}

Animals: Five fresh cadaver heads from already dead female Arabian foals (8-12 weeks old) without a history of head problems were obtained from another project which was supported by TUBITAK-KAMAG (The Scientific And Technological Research Council of Turkey-National Scientific Meetings Grant Programme). The heads were disarticulated from the atlantoaxial joint and prepared for CT examination. All procedures were conducted following a protocol approved by the Ethical committee of the Faculty of Veterinary Medicine, Selcuk University (SUVFEK 2011/099).

CT scanning: CT scans were obtained using a Spiral CT scanner (Aquilon 4, Toshiba, Tokyo, Japan). The scan settings were $120 \mathrm{kV}, 175 \mathrm{mAs}, 38 \mathrm{~cm}$ diameter and a matrix of 

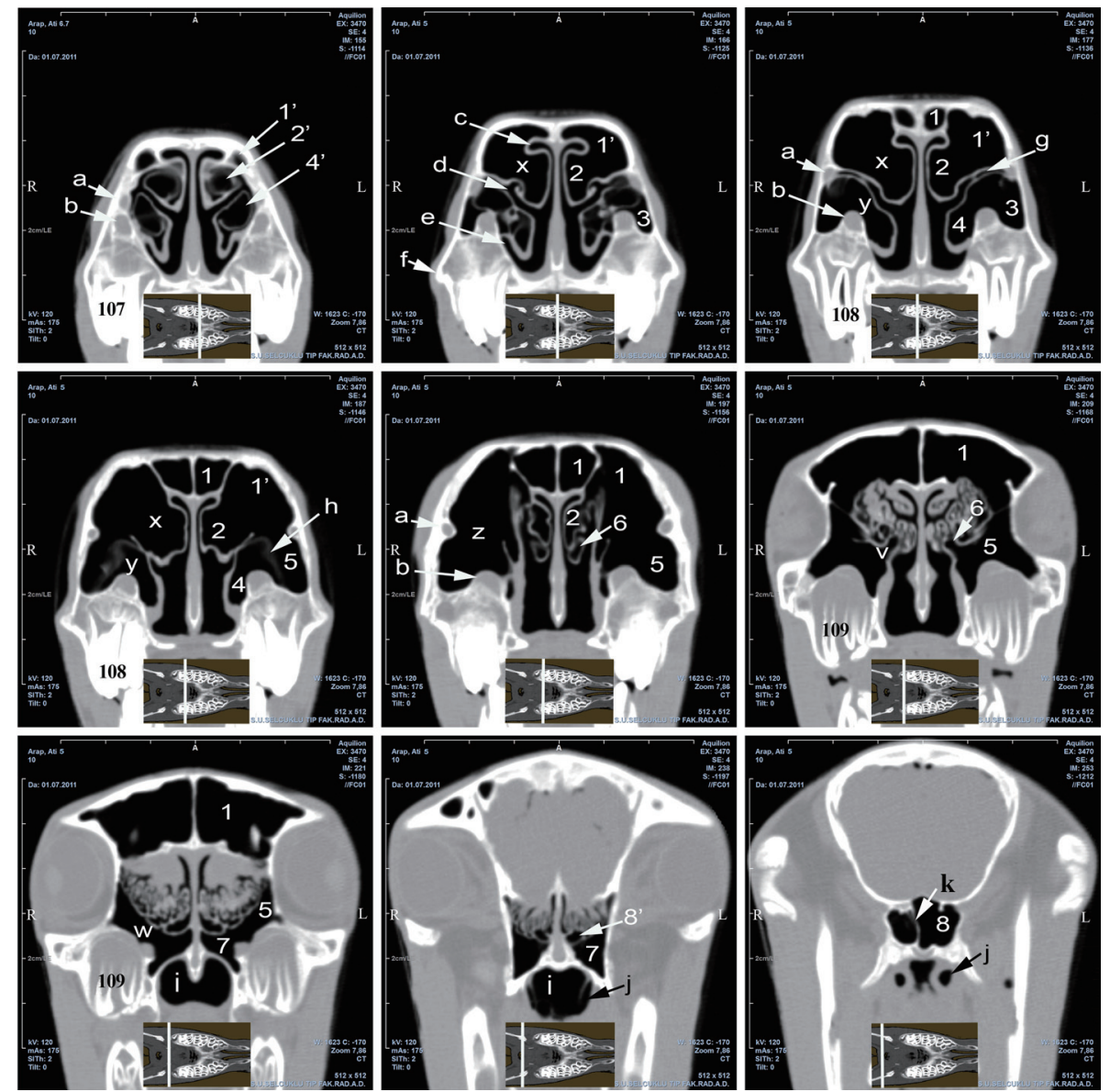

Fig. 1. Transverse CT images (rostrocaudal direction, interval $12 \mathrm{~mm}$ ) of paranasal sinuses, foal 4 (12 weeks). The white line of each inserted picture which is a common dorsal plane image shows the slice position for each transverse image: 1, Frontal sinus (FS); 1', rostral portion of FS; 2, Dorsal conchal sinus (DCS); 2', dorsal conchal bulla; 3, Rostral maxillary sinus (RMS); 4, Ventral conchal sinus (VCS); 4', ventral conchal bulla; 5, Caudal maxillary sinus (CMS); 6, Middle conchal sinus (MCS); 7, Palatine sinus (PS); 8, Sphenoid sinus (SS); 8', Sphenoidal aperture (SA, between SS and ventral ethmoidal meatus); $x$, Conchofrontal aperture (CFA); y, Conchomaxillary aperture (CMA); $z$, Frontomaxillary aperture (FMA), v, aperture between MCS and CMS; w, Sphenopalatinal aperture (SPA); a, nasolacrimal canal; b, infraorbital canal; c, dorsal nasal meatus; d, middle nasal meatus; e, ventral nasal meatus; f, facial crest; g, Nasomaxillary aperture (NMA); h, maxillary septum between 3 and 5 ; i, nasopharynx; $j$, auditory tube; $\mathrm{k}$, sphenoidal septum; 1 , infraorbital foramen; $\mathrm{m}$, joint of the zygomatic processes of temporal bone; $\mathrm{n}$, supraorbital foramen.

$512 \times 512$. The heads were placed on the CT table such that the ventral margin of the mandible was in complete contact with the table and were scanned in the rostrocaudal direction at $1 \mathrm{~mm}$ intervals. Transverse CT images of the heads were recorded on CD-ROMs in Digital Imaging and Communication in Medicine (DICOM) format (Fig. 1), whereas dorsal and sagittal plane images obtained by reformatting of these images were recorded on different CD-ROMs in CINE format (Figs. 3 and 4).

Anatomical sections: The heads were kept in a freezer for $48 \mathrm{hr} ; 2.5 \mathrm{~cm}$ serial anatomical sections were obtained in the CT scan positions using an electrical band saw. Following photography of the specimens, they were placed in
$10 \%$ formalin solution. Transverse CT images that contained paranasal sinuses were identified, and the details of these images were compared with the corresponding anatomical sections (Fig. 2).

Segmentation and $3 D$ modeling: The $3 \mathrm{D}$ reconstructions of the paranasal sinuses and skull were obtained using the MIMICS (Materialise's Interactive Medical Image Control System, ver: 12.01, Materialise, Leuven, Belgium) program. The serial CT images of the head in DICOM form were read into MIMICS software. The main procedures involved segmentation of serial CT images and 3D modeling of the regions of interest (ROI) [8]. The CT images were first segmented using segmentation tools (threshold, region growing 


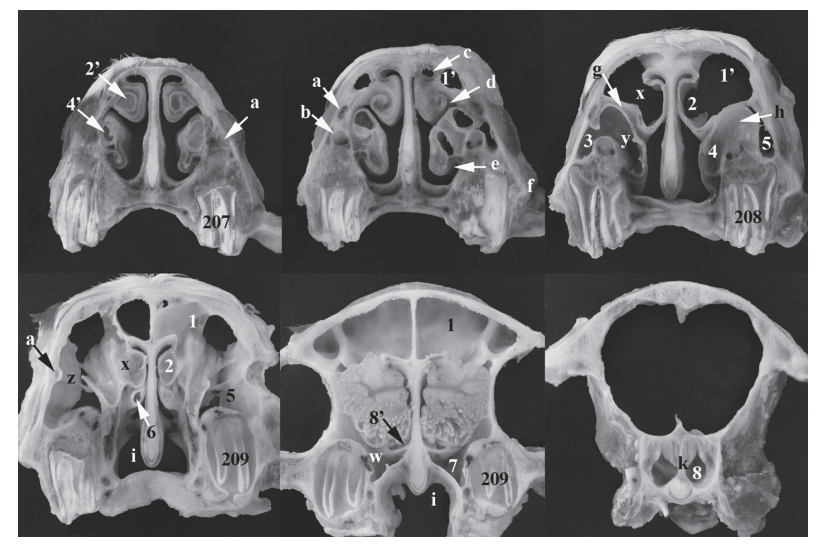

Fig. 2. Transverse anatomical sections (rostrocaudal direction, interval $25 \mathrm{~mm}$ ) of paranasal sinuses, foal 4 (12 weeks). See legend to Fig. 1 for details.

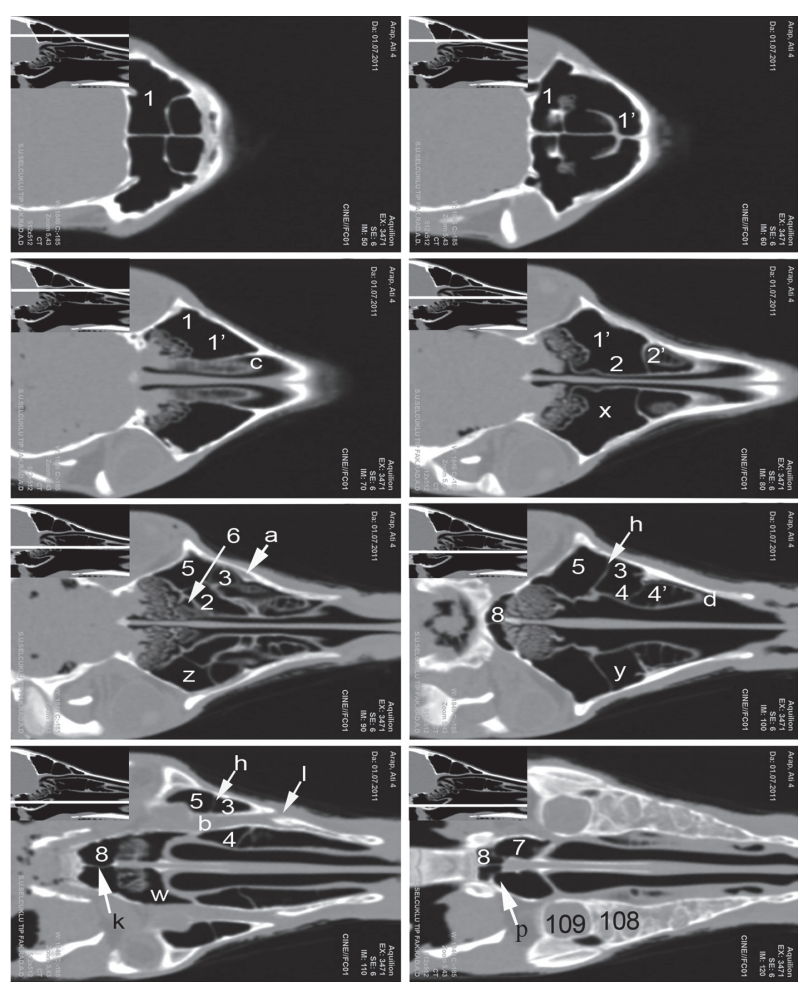

Fig. 3. Reformatted dorsal plane images (dorsoventral direction, interval $8 \mathrm{~mm}$ ), foal 3 (11 weeks). The white line of each inserted picture which is a common sagittal plane image shows the slice position for each dorsal image. p, aperture between SS and PS. See legend to Fig. 1 for other details.

and edit mask) to extract the paranasal sinuses and skull, and $3 \mathrm{D}$ models of the skull were created after isolation by setting the gray level threshold (350 to 1,000 HU). Imaging data for the paranasal sinuses were isolated by setting the gray level thresholds ( -200 to $-1,024 \mathrm{HU})$ to obtain an air rim [31]. The total sinus surface area was determined after modeling

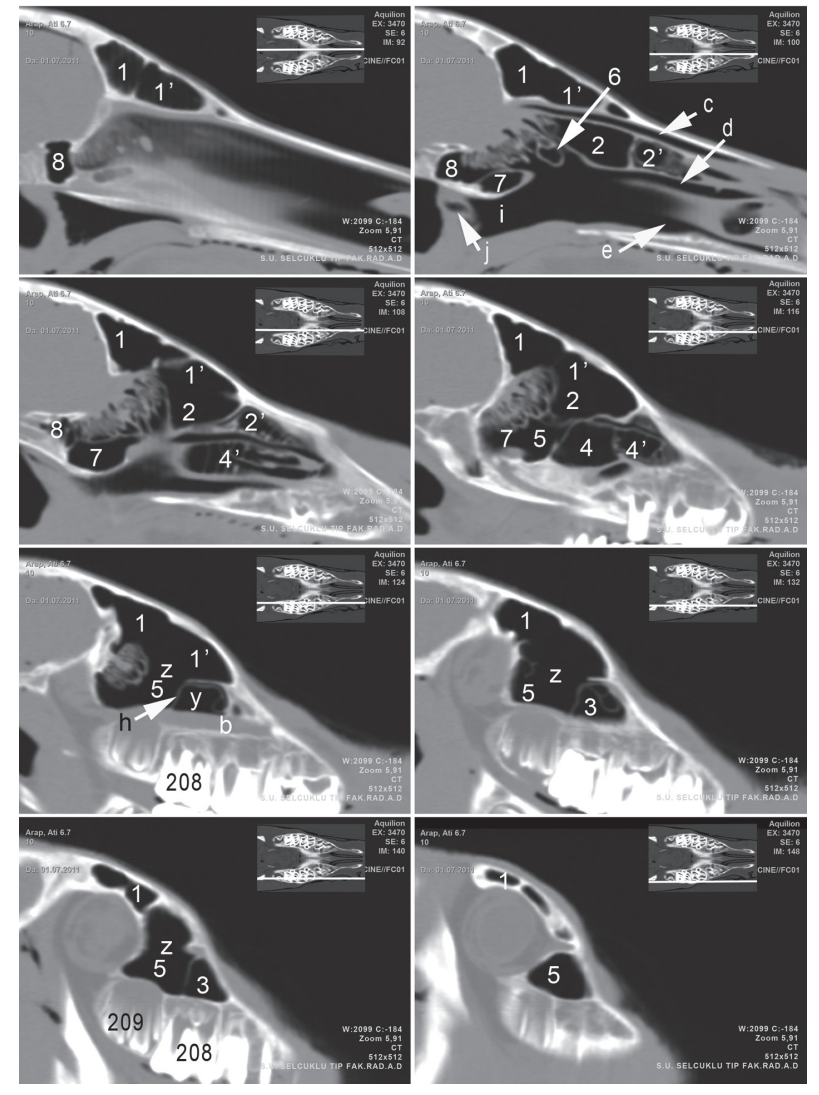

Fig. 4. Reformatted sagittal plane images (left mediolateral direction, interval $8 \mathrm{~mm}$ ), foal 4 (12 week). The white line of each inserted picture which is a common dorsal plane image shows the slice position for each sagittal image. See legend to Fig. 1 for details.

the right and left sinuses using the "3D calculate" routine of the program. Following this procedure, imaging data for the sinuses were manually separated from each other using the "3D edit mask" routine of the program, and a 3D model of each sinus was created with masks in different colors (Fig. 5). The volumes of the sinuses, as well as the length and width of the apertures connecting these sinuses, were measured using these models, and the orientation of the apertures was identified.

Paranasal sinus boundaries: In this part of the research, the planes bounding the paranasal sinuses were determined on a 3D model of the skull, which was made semitransparent. The relationships of these planes with the skull, as well as the location of the sinuses in the volume created by the intersection of these planes, were investigated. For this purpose, images taken from the models in JPG format from lateral, medial and dorsal perspectives were examined using Gimp (GNU Image Manipulation Program). Two main planes were drawn: a horizontal plane passing through the ventral margin of the mandible on the lateral and medial images of the 3D models and a medial sagittal plane on the dorsal image (Fig. 6A and 6B). The sinuses were bounded 

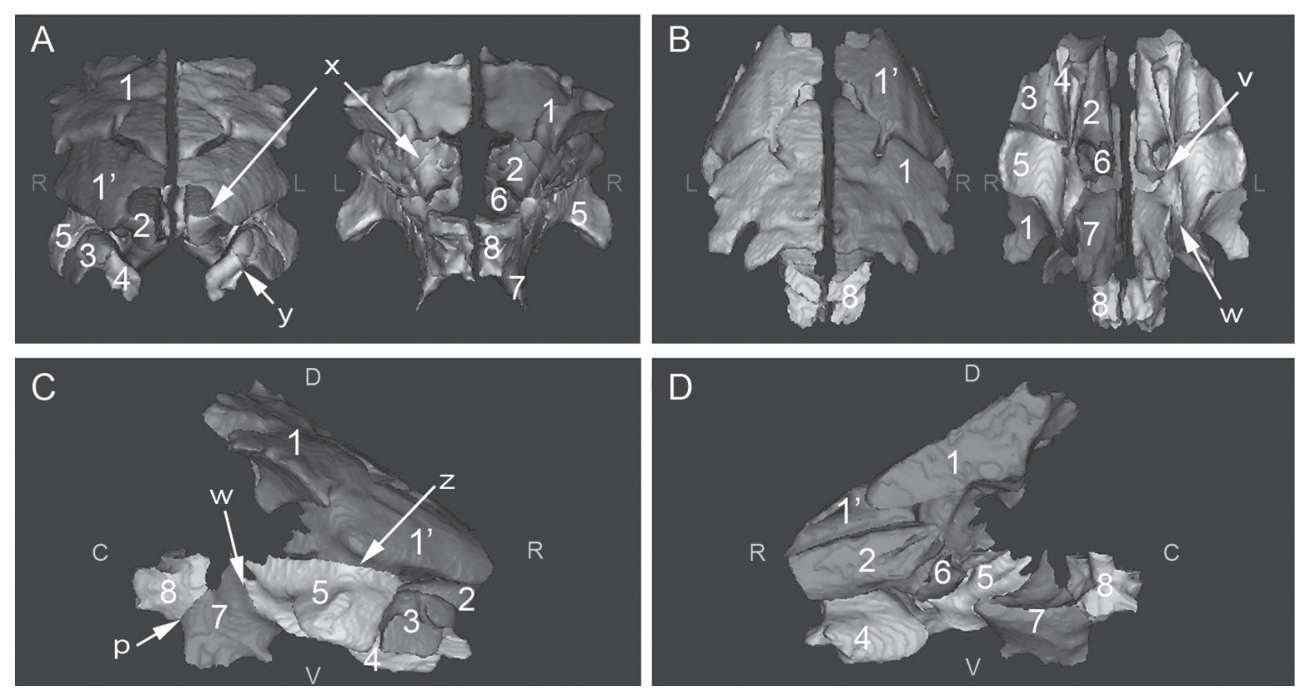

Fig. 5. Visualization of 3D models of paranasal sinuses of foals from different perspectives foal 5 (12 weeks): A, rostral (left) and caudal (right) views; B, dorsal (left) and ventral (right) views; C, lateral (right) view; D, medial (right) view. p, aperture between SS and PS. See legend to Fig. 1 for other details.
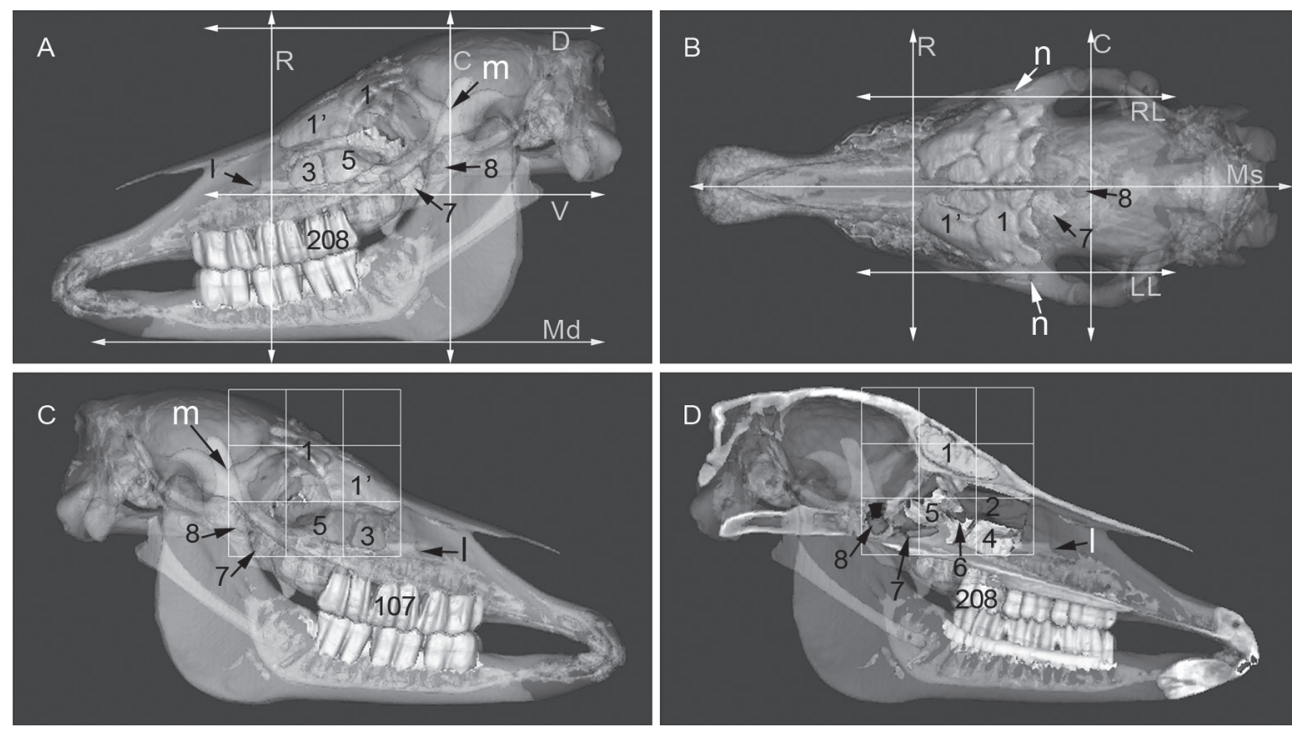

Fig. 6. 3D models of the skull (semitransparent) and paranasal sinuses (different colors and opaque) and the planes bordering the sinuses, foal 5 (12 weeks): A, left lateral view; B, dorsal view; C, right lateral view; D, left median view; R, rostral transverse plane; C, caudal transverse plane; D, dorsal plane; V, ventral plane; Md, mandibular plane; RL, right lateral plane; LL, left lateral plane; Ms, median sagittal plane. See legend to Fig. 1 for other details.

from the rostral and caudal aspects by a line perpendicular to the horizontal plane; from the ventral and dorsal aspects by a parallel line; and from the right and left lateral aspects by two planes parallel to the medial sagittal plane. However, the dorsal plane was drawn so as to be tangential to the dorsal boundary of the skull. Moreover, 2 planes were drawn between the rostral-caudal and dorsal-ventral planes and parallel to these planes on the medial and lateral images, and the location of the sinuses was investigated in the grid area thus created (Fig. 6C and 6D).

In the present study, the nomenclature used for the anatomical details of the paranasal region and the boundaries between the sinuses was based on equine anatomy texts [4, $14,24,32]$, anatomical papers [23, 29, 36, 37] and the Nomina Anatomica Veterinaria(NAV) [12].

Statistical analysis: Morphometric data on the volume and surface area of the right and left sinuses were evaluated by the Two sample $t$-test, whereas the relation between the 
Table 1. Estimated volumes of the paranasal sinuses using 3D models and correlations between left and right sinuses

\begin{tabular}{ccccccc}
\hline \multicolumn{3}{c}{ Mean \pm SEM $\left(\mathrm{cm}^{3}\right),(\mathrm{CV})$, Ratio (\%) } & \multicolumn{2}{c}{ Correlation } \\
\hline Sinuses & Left & \multicolumn{1}{c}{ Right } & R & P \\
\hline FS & $41.2 \pm 3.4(0.18)$ & 55.7 & $41.7 \pm 4.5(0.24)$ & 58 & 0.977 & $0.004^{* *}$ \\
DCS & $7.1 \pm 0.8(0.26)$ & 9.6 & $7.4 \pm 0.9(0.28)$ & 10.4 & 0.944 & $0.016^{* *}$ \\
CMS & $11.8 \pm 1.9(0.36)$ & 16 & $11.0 \pm 1.6(0.33)$ & 15.3 & 0.973 & $0.005^{* *}$ \\
RMS & $3.5 \pm 0.4(0.25)$ & 4.7 & $3.2 \pm 0.4(0.27)$ & 4.5 & 0.926 & $0.024^{* *}$ \\
VCS & $4.2 \pm 0.4(0.21)$ & 5.6 & $3.0 \pm 0.4 *(0.36)$ & 4.2 & 0.619 & 0.266 \\
MCS & $0.2 \pm 0.1(1.37)$ & 0.3 & $0.2 \pm 0.1(1.48)$ & 0.3 & 0.993 & $0.001^{* *}$ \\
PS & $3.7 \pm 0.6(0.35)$ & 5 & $3.7 \pm 0.9(0.53)$ & 5.1 & 0.859 & 0.063 \\
SS & $2.3 \pm 0.6(0.55)$ & 3.1 & $1.7 \pm 0.5(0.67)$ & 2.3 & 0.71 & 0.179 \\
Total volume & $74.0 \pm 7.3(0.22)$ & 100 & $71.8 \pm 8.6(0.27)$ & 100 & 0.982 & 0.003 \\
\hline
\end{tabular}

*Different from the same line $(P<0.05)$. **Positive correlation was determined between left and right sinuses volumes $(P<0.05)$.

Table 2. The length, width, orientation and shape of openings between paranasal sinuses in foals (Mean $\pm \mathrm{SEM}$ )

\begin{tabular}{lcccc}
\hline \multicolumn{1}{c}{ Opening } & Length $(\mathrm{mm})$ & Width $(\mathrm{mm})$ & Orientation & Shape \\
\hline CFA $(\mathrm{n}=5)^{\mathrm{a}}$ & $37.83 \pm 1.5$ & $15.8 \pm 0.4$ & Sagittal oblique & Triangle \\
FMA $(\mathrm{n}=5)^{\mathrm{b}}$ & $22.6 \pm 1.2$ & $13.9 \pm 1.2$ & Dorsal & Elliptic \\
CMA $(\mathrm{n}=5)^{\mathrm{a}}$ & $22.5 \pm 1.0$ & $10.0 \pm 0.5$ & Sagittal oblique & Quadrilateral \\
SPA $(\mathrm{n}=5)^{\mathrm{c}}$ & $18.8 \pm 1.0$ & $4.1 \pm 0.5$ & Sagittal oblique & Comma \\
NAM $(\mathrm{n}=5)$ & NA & NA & NA & Slit \\
Aperture between SS and PS $(\mathrm{n}=2)^{\mathrm{c}}$ & $10.8 \pm 0.4$ & $9.0 \pm 0.6$ & Transverse oblique & Semicircular \\
\hline
\end{tabular}

a) Length: rostrocaudal, Width (=height): dorsoventral oblique, b) Length: rostrocaudal, Width: mediolateral, c) Length (=height): dorsoventral oblique, Width: mediolateral. NA: Not Available

right and left sinuses was evaluated by Pearson's correlation test in SPSS (Statistical Package for the Social Sciences, Chicago, IL, U.S.A. 19.0 ed, 2010). $P<0.05$ were considered to represent statistical significance.

\section{RESULTS}

$2 D$ image data: Anatomical details of the paranasal sinuses of the foals were demonstrated on transverse CT images (Fig. 1), anatomical sections (Fig. 2) and the images of the dorsal plane (Fig. 3) and median sagittal plane (Fig. 4). Evaluations performed using CT images and anatomical gross sections revealed that the right and left anatomical configurations of the region, except for the right and left sphenoid sinuses (SS) and the osseous septum separating these sinuses (Figs. 1-3), have completely symmetric organization.

It was observed in the foals that the DCS, which was located on the rostromedial aspect of the FS, was connected with the FS via a large aperture (conchofrontal aperture $=\mathrm{CFA}$ ), to form the conchofrontal sinus (Figs. 1-3 and $5 \mathrm{x}$ ). The CMS was connected with the FS via the frontomaxillary aperture (FMA) on the dorsal aspect (Figs. 1-5 z), with the palatine sinus (PS) via the sphenopalatinal aperture (SPA) on the caudoventral aspect (Figs. 1-3 and $5 \mathrm{w}$ ) and with the MCS via a narrow aperture on the medial aspect (Figs. 1 and 5 v). The RMS, which was located on the dorsal aspect of 4th deciduous premolar teeth (DP4) (108 or 208 Triadan system), was connected with the VCS, which was connected to the medial aspect of DP4 via the conchomaxillary aperture
(CMA) (Figs. 1-5 y). The RMS and CMS were connected with the middle nasal meatus via the nasomaxillary aperture (NMA) on the dorsal aspect of $\mathrm{DP}_{4}$ (Figs. 1 and $2 \mathrm{~g}$ ). In three of the foals, the SS communicated rostrally with the ventral ethmoidal meatus (Figs. 1 and 28 '), whereas the SPS composed of SS and PS communicated via a large aperture in two foals (Figs. 3 and 5 p).

$3 D$ modeling data for the paranasal sinuses: Details of the sinuses in the 3D models were demonstrated on the images taken from different perspectives (Figs. 5 and 6). Morphometric measurements performed on the models were used primarily to determine the surface areas of the right and left paranasal sinuses, which were found to be $209.2 \pm 18.1$ $\mathrm{cm}^{2}$ and $219.5 \pm 15.8 \mathrm{~cm}^{2}$, respectively. This morphometric measurement showed a strong correlation between the right and left paranasal sinuses of each foal $(\mathrm{r}=0.97, P<0.05)$. The results of the volumetric evaluation of the right and left paranasal sinuses are demonstrated in Table 1. While there was no correlation between the right and left VCS, PS and SS volumes $(P>0.05)$, a positive correlation close to 1.0 was observed for other pairs of sinuses (Table $1, P<0.05$ ). The FS was the largest sinus, whereas the MCS was the smallest sinus in the foals, and the VCS had a larger volume on the left side (in all animals) (Table 1).

The length, width, orientation and shape of the apertures that connect the sinuses in foals were determined by linear measurements on the 3D models and by gross evaluation (Table 2).

Paranasal sinus boundaries: On the 3D models, it was 
observed that the rostral border of the sinuses was formed by the rostral aspect of the FS, and the transverse plane crossing this point (the rostral plane) passes through the middle point of the labial surface of 3rd deciduous premolar teeth $\left(\mathrm{DP}_{3}\right)$ (107 or 207) (Fig. 6A and 6B). The caudal border of all the sinuses was formed by the caudal aspect of the SS, and the transverse plane crossing this point (the caudal plane) passed through the angle formed by the joint of the zygomatic processes of temporal bone (Fig. 6). The ventral border of all the sinuses was formed by the ventral margin of the PS and VCS, and the ventral plane crossing this point passed through the ventral margin of the infraorbital foramen (Fig. 6 ). The borders of the right and left lateral sinuses were formed by the lateral aspects of the CMS, and the lateral planes crossing this point passed through the medial margin of the supraorbital foramen (Fig. 6B). It was observed that the sinuses generally display a precise location in the region created by drawing two planes at equal distances and parallel to the rostral-caudal and dorsal-ventral planes on the lateral and medial images (Fig. 6C and 6D).

\section{DISCUSSION}

CT imaging may be effectively used in horses either to determine sectional anatomical details or to detect pathological conditions of the skull. In the studies in which evaluations have been performed primarily using transverse CT images $[1,23,29,36,37]$, the heads have been placed on the CT table in different positions, and there are angular differences between the images of different animals. This unfavorable condition may affect the evaluation, comprehension and comparison of anatomical details on the transverse CT images presented in these studies. In the present study, all heads were placed such that the ventral margin of the mandible had complete contact with the CT table; thus, angular differences between transverse CT images were minimized. Serial transverse CT images obtained in this position were compared with anatomical sections, and details of the paranasal sinuses were determined (Figs. 1 and 2). Moreover, these details were demonstrated on images from the dorsal (Fig. 3) and sagittal (Fig. 4) planes.

The paranasal sinuses have been successfully modeled in studies conducted on humans [15, 28, 34, 38], hominoids [30], bovine species [10], rabbits [5], predatory and armored dinosaurs [41], some monkeys [25], rodents [27] and felids [35] by using $3 \mathrm{D}$ modeling programs. The present study, which modeled the left and right paranasal sinuses and their subdivisions in Arabian foals, is the first modeling study conducted on this species (Figs. 5 and 6). Paranasal sinus volumes have been measured using cadavers by directly injecting a variety of materials $[33,40]$ using CT images [2, $9,11,31,39]$ and using 3D digital models [10, 15, 16, 20, $25,27,28,30,34,38,39]$. The present study measured the volumes of the paranasal sinuses on 3D models (Table 1). Nickel et al. [24], Hillmann [14] and Barone [4] reported that the sinuses continue to enlarge up to 5-year-old in horses, when the head becomes mature, and that the maxillary sinus is the largest in adult horses (this information has not been based on any morphometric data). It was detected in the Arabian foals that the FS was the largest at a rate of $56.7 \%$, the maxillary sinus was the second largest at a rate of $20.3 \%$ and the MCS was the smallest at a rate of $0.3 \%$ (Table 1). Considering current literature and the results of the present study, it can be said that the most significant volumetric change up to the 5th year of a horse occurs in the maxillary sinus. However, morphometric studies that compare young and mature animals are needed to investigate this phenomenon.

In the studies performed on the paranasal sinuses of horses using CT, an asymmetric appearance in anatomical configuration usually indicates a pathological condition $[13,18,36$, 42]. We failed to find a morphometric study performed on this subject in animals. The present study found a correlation close to 1.0 between the right and left sinus volumes, except for the VCS, PS and SS ( $P>0.05$, Table. 1). The left VCS in the foals was observed to be larger than the right (Table 1). It has been reported that the osseous septum that separates the sphenoidal parts of SPS from each other in horses is usually not placed in the midline [14, 24]. Nickel et al. [24] reported that sphenoidal part does not exist in some animals and, if it exists, it rarely opens into the ventral ethmoidal meatus. However, Hillmann [14] reported that this sinus opens directly into the ventral ethmoidal meatus in one-third of horses. The present study demonstrated that the osseous septum separating the right and left SS was placed in the median plane in three animals, and the SS of these animals opened directly into the ventral conchal meatus. PS seperating from SS with an osseous septum opened directly caudal maxillary sinus in these animals. However, the osseous septum was not placed in the median plane in two animals, and the SS and SP formed the SPS in these animals.

Information about the apertures that connect the paranasal sinuses has been described in detail in anatomical papers $[23,29,37]$ and textbooks $[4,14,24,32]$, but these references have some differences in terms of the number of apertures and nomenclature. In response to the absence of a name in the NAV [12], Morrow et al. [23] named the aperture between the FS and DCS the CFA. The present study considered this aperture to be the border between the FS and DCS. Moreover, the aperture of the SS, which was bilateral in three animals, which opens into the ventral ethmoidal meatus, was named the sphenoidal aperture (SA) (Figs. 1 and 2). The length, width and orientation of the CMS, NMA, FMA and SPA were first defined in a study performed using transverse CT images [29]. The present study is the first in which $3 \mathrm{D}$ models were used in the determination of the length, width, orientation and shape of the sinuses (Table 2). Although the results of the present study show similarities with results of Probst et al. [29] in terms of orientation, they differ in terms of length and width. We attribute this result to the different ages of the animals used in the two studies. Morphometric evaluations of orientation, length and width, etc., performed using 3D models should give more accurate results than $2 \mathrm{D}$ images.

Although previous reports $[4,14,24]$ have described the topography of the paranasal sinuses of the horse in detail, in- 
formation about the planes that bound these sinuses is quite limited. The present study revealed that the planes which bound the sinuses pass through palpable points in the head of the foal (Fig. 6A and 6B). Moreover, the location of the sinuses was demonstrated in the grid area that was formed by the planes drawn parallel to the above-mentioned planes (Fig. 6C and 6D). This information should be useful to clinicians during the examination of living animals, particularly during lateral radiographic evaluation.

In conclusion, although images obtained from CT are used in treatment planning, diagnosis and education, there are some limitations relating to the detailed morphometry and spatial relationships between paranasal sinuses and other structures. 3D modeling, in combination with conventional sectional imaging, of the paranasal sinuses of foals will improve the level of knowledge about this region and may help both students and clinicians.

ACKNOWLEDGMENTS. Preliminary results of this study presented in abstract form at 7 th National Veterinary Anatomy Congress, Antalya, Turkey, October 2011 and the 1st International Biology Congress, Bishkek, Kyrgyzstan, September 2012.

\section{REFERENCES}

1. Arencibia, A., Vazquez, J. M., Rivero, M., Latorre, R., Sandoval, J. A., Vilar, J. M. and Ramirez, J. A. 2000. Computed tomography of normal cranioencephalic structures in two horses. Anat. Histol. Embryol. 29: 295-299. [Medline] [CrossRef]

2. Ariji, Y., Ariji, E., Yoshiura, K. and Kanda, S. 1996. Computed tomographic indices for maxillary sinus size in comparison with the sinus volume. Dentomaxillofac. Radiol. 25: 19-24. [Medline]

3. Avella, C. S. and Perkins, J. D. 2011. Computed tomography in the investigation of trauma to the ventral cranium. Equine Vet. Educ. 23: 333-338. [CrossRef]

4. Barone, R. 1999. pp. 216-235. Anatomie Comparee des Mammififeres Domestiques, Vigot Preres, Paris.

5. Casteleyn, C., Cornillie, P., Hermens, A., Van Loo, D., Van Hoorebeke, L., Van den Broeck, W. and Simoens, P. 2010. Topography of the rabbit paranasal sinuses as a prerequisite to model human sinusitis. Rhinology 48: 300-304. [Medline]

6. Cissell, D. D., Wisner, E. R., Textor, J., Mohr, F. C., Scrivani, P. V. and Theon, A. P. 2012. Computed tomographic appearance of equine sinonasal neoplasia. Vet. Radiol. Ultrasound. 53: 245-251. [Medline]

7. De Zani, D., Borgonovo, S., Biggi, M., Vignati, S., Scandella, M., Lazzaretti, S., Modina, S. and Zani, D. 2010. Topographic comparative study of paranasal sinuses in adult horses by computed tomography, sinuscopy, and sectional anatomy. Vet. Res. Commun. 34: S13-S16. [Medline] [CrossRef]

8. Ding, H. M., Yin, Z. X., Zhou, X. B., Li, Y. B., Tang, M. L., Chen, S. H., Xu, D. C. and Zhong, S. Z. 2008. Three-dimensional visualization of pelvic vascularity. Surg. Radiol. Anat. 30: 437-442. [Medline] [CrossRef]

9. Emirzeoglu, M., Sahin, B., Bilgic, S., Celebi, M. and Uzun, A. 2007. Volumetric evaluation of the paranasal sinuses in normal subjects using computer tomography images: A stereological study. Auris. Nasus. Larynx 34: 191-195. [Medline] [CrossRef]

10. Farke, A. A. 2010. Evolution and functional morphology of the frontal sinuses in Bovidae (Mammalia: Artiodactyla), and impli- cations for the evolution of cranial pneumaticity. Zool. J. Linn. Soc. Lond. 159: 988-1014. [CrossRef]

11. Fernandez, J. M. S., Escuredo, J. A. A., Del Rey, A. S. and Montoya, F. S. 2000. Morphometric study of the paranasal sinuses in normal and pathological conditions. Acta Oto-Laryngol. 120: 273-278. [CrossRef]

12. Frewein, J. and Habel, R. E. 2012. Nomina Anatomica Veterinaria, 5th ed., World Association of Veterinary Anatomists, Hannover, Germany.

13. Henninger, W., Frame, E. M., Willmann, M., Simhofer, H., Malleczek, D., Kneissl, S. M. and Mayrhofer, E. 2003. CT features of alveolitis and sinusitis in horses. Vet. Radiol. Ultrasound. 44: 269-276. [Medline] [CrossRef]

14. Hillmann, D. J. 1975. Skull. pp. 318-348. In: Sisson and Grossman's The Anatomy of the Domestic Animals, 5th ed. (Rosenbaum, C. E., Ghoshal, N. G. and Hillmann, D. J. eds.), Saunders, Philadelphia.

15. Kawarai, Y., Fukushima, K., Ogawa, T., Nishizaki, K., Gunduz, M., Fujimoto, M. and Masuda, Y. 1999. Volume quantification of healthy paranasal cavity by three-dimensional CT imaging. Acta. Otolaryngol. Suppl. 540: 45-49. [Medline]

16. Kim, H. J., Yoon, H. R., Kim, K. D., Kang, M. K., Kwak, H. H., Park, H. D., Han, S. H. and Park, C. S. 2003. Personal-computerbased three-dimensional reconstruction and simulation of maxillary sinus. Surg. Radiol. Anat. 24: 393-399. [Medline]

17. Kinns, J. and Pease, A. 2009. Computed tomography in the evaluation of the equine head. Equine Vet. Educ. 21: 291-294. [CrossRef]

18. Kowalczyk, L., Boehler, A., Brunthaler, R., Rathmanner, M. and Rijkenhuizen, A. B. M. 2011. Squamous cell carcinoma of the paranasal sinuses in two horses. Equine Vet. Educ. 23: 435-440. [CrossRef]

19. Kraft, S. L. and Gavin, P. 2001. Physical principles and technical considerations for equine computed tomography and magnetic resonance imaging. Vet. Clin. North Am. Equine Pract. 17: 115-130. [Medline]

20. Kunkel, M. E., Moral, A. I., Tingelhoff, K., Bootz, F. and Wahl, F. 2009. Validity of paranasal CT image reconstruction for finite element models in otorhinolaryngology. Comp. Meth. Appl. Sci. 13: $273-286$.

21. Li, W. Z., Zhang, M. C., Li, S. P., Zhang, L. T. and Huang, Y. 2009. Application of computer-aided three-dimensional skull model with rapid prototyping technique in repair of zygomaticoorbito-maxillary complex fracture. Int. J. Med. Robot. 5: 158-163. [Medline] [CrossRef]

22. Manso-Díaz, G. and Taeymans, O. 2012. Imaging diagnosisnasofrontal suture exostosis in a horse. Vet. Radiol. Ultrasound. 53: 573-575. [Medline] [CrossRef]

23. Morrow, K. L., Park, R. D., Spurgeon, T. L., Stashak, T. S. and Arceneaux, B. 2000. Computed tomographic imaging of the equine head. Vet. Radiol. Ultrasound. 41: 491-497. [Medline] [CrossRef]

24. Nickel, R., Schummer, A. and Seiferle, E. 1979. pp. 211-225. The Viscera of Domestic Mammals, 2nd ed., Verlag Paul Parey, Berlin.

25. Nishimura, T. D., Takai, M., Tsubamoto, T., Egi, N. and Shigehara, N. 2005. Variation in maxillary sinus anatomy among platyrrhine monkeys. J. Hum. Evol. 49: 370-389. [Medline] [CrossRef]

26. Pham, A. M., Raffi, A. A., Metzger, M. C., Jamali, A. and Strong, E. B. 2007. Computer modeling and intraoperative navigation in maxillofacial surgery. Otolaryngol Head Neck Surg. 137: 624-631. [Medline] [CrossRef] 
27. Phillips, J. E., Ji, L., Rivelli, M. A., Chapman, R. W. and Corboz, M. R. 2009. Three-dimensional analysis of rodent paranasal sinus cavities from X-ray computed tomography (CT) scans. Can. J. Vet. Res. 73: 205-211. [Medline]

28. Pirner, S., Tingelhoff, K., Wagner, I., Westphal, R., Rilk, M., Wahl, F. M., Bootz, F. and Eichhorn, K. W. G. 2009. CT-based manual segmentation and evaluation of paranasal sinuses. Eur. Arch. Otorhinolaryngol. 266: 507-518. [Medline] [CrossRef]

29. Probst, A., Henninger, W. and Willmann, M. 2005. Communications of normal nasal and paranasal cavities in computed tomography of horses. Vet. Radiol. Ultrasound. 46: 44-48. [Medline] [CrossRef]

30. Rae, T. C. and Koppe, T. 2000. Isometric scaling of maxillary sinus volume in hominoids. J. Hum. Evol. 38: 411-423. [Medline] [CrossRef]

31. Sahlstrand-Johnson, P., Jannert, M., Strömbeck, A. and AbulKasim, K. 2011. Computed tomography measurements of different dimensions of maxillary and frontal sinuses. BMC Medical Imaging 11: 8 http://www.biomedcentral.com/1471-2342/11/8. [Medline] [CrossRef]

32. Schaller, O. 1992. pp. 178-181. Illustrated Veterinary Anatomical Nomenclature., Ferdinand Enke Verlag, Stuttgart.

33. Schumacher, G. H., Heyne, H. J. and Fanghanel, R. 1972. Anatomy of the human paranasal sinuses. 2. Volumetric measurement. Anatomischer Anzeiger 130: 143-157. [Medline]

34. Shi, H. S., Scarfe, W. C. and Farman, A. G. 2006. Maxillary sinus 3D segmentation and reconstruction from cone beam CT data sets. Int. J. CARS. 1: 83-89. [CrossRef]

35. Siliceo, G., Salesa, M. J., Anton, M., Pastor, J. F. and Morales, J. 2011. Comparative anatomy of the frontal sinuses in the primitive sabre-toothed felid Promegantereon ogygia (Felidae, Machairodontinae) and similarly sized extant felines. Estud. Geol-Madrid 67: 277-290. [CrossRef]

36. Smallwood, J. E., Wood, B. C., Taylor, E. and Tate, L. P. 2002. Anatomic reference for computed tomography of the head of the foal. Vet. Radiol. Ultrasound. 43: 99-117. [Medline] [CrossRef]

37. Solano, M. B., R. S. 2004. CT of the Equine Head: Technical Considerations, Anatomical Guide, and Selected Diseases. Clin. Tech. Equine. Pract. 3: 374-388.

38. Tingelhoff, K., Eichhorn, K. W. G., Wagner, I., Kunkel, M. E., Moral, A. I., Rilk, M. E., Wahl, F. M. and Bootz, F. 2008. Analysis of manual segmentation in paranasal CT images. Eur. Arch. Otorhinolaryngol. 265: 1061-1070. [Medline] [CrossRef]

39. Tingelhoff, K., Moral, A. I., Kunkel, M. E., Rilk, M., Wagner, I., Eichhorn, K. W. G., Wahl, F. A. and Bootz, F. 2007. Comparison between manual and semi-automatic segmentation of nasal cavity and paranasal sinuses from CT images. Conf. Proc. IEEE Eng. Med. Biol. Soc 5505-5508. [Medline]

40. Uchida, Y., Goto, M., Katsuki, T. and Akiyoshi, T. 1998. A cadaveric study of maxillary sinus size as an aid in bone grafting of the maxillary sinus floor. J. Oral Maxillofac. Surg. 56: 1158-1163. [Medline] [CrossRef]

41. Witmer, L. M. and Ridgely, R. C. 2008. The paranasal air sinuses of predatory and armored dinosaurs (archosauria: theropoda and ankylosauria) and their contribution to cephalic structure. Anat. Rec. (Hoboken) 291: 1362-1388. [Medline] [CrossRef]

42. Witte, T. H. and Perkins, J. D. 2011. Early diagnosis may hold the key to the successful treatment of nasal and paranasal sinus neoplasia in the horse. Equine Vet. Educ. 23: 441-447. [CrossRef] 